\title{
A EDUCAÇÃO COMPARADA E SUA ARQUITETURA HISTÓRICA
}

\author{
COMPARATIVE EDUCATION AND ITS HISTORIC \\ ARCHITECTURE
}

\author{
João Jorge Correa*
}

\begin{abstract}
RESUMO
Enquanto campo de investigação e procedimento metodológico de pesquisa, a educação comparada é um terreno fértil e com amplas perspectivas pela sua potencialidade, que pode ser verificada em várias subáreas das ciências humanas e das ciências sociais. Trata-se de um espaço de construção do conhecimento situado nas fronteiras da elaboração desse saber que é necessariamente interdisciplinar. Neste artigo discute-se a educação comparada e o método comparatista no campo educativo. O texto está organizado em duas partes. Na primeira parte faz-se uma breve incursão acerca dos principais enfoques que a educação comparada vem recebendo ao longo do tempo. Na segunda, apresenta-se uma exposição da arquitetura da educação comparatista, a partir dos autores fundamentais que trataram do tema. Concluindo, apontam-se alguns limites e possibilidades no uso da educação comparada, assim como elementos para futuras reflexões e pesquisas.
\end{abstract}

Palavras-chave: Educação Comparada. História da Educação Comparada. Metodologia Comparatista. Interdisciplinaridade.

\begin{abstract}
As a field of investigation and methodological research procedure, comparative education is a rich and broad field for its potential, which can be seen in several areas of the humanities and social sciences. It is a space of knowledge building situated between the borders of the elaboration of interdisciplinary knowledge. This article discusses compared education and the comparative method in the educational field. The text is organized into two parts. The first part presents a brief review of the main approaches used in comparative education over time. The second part presents the features of comparative education based on the main authors who addressed the issue. Finally, the article points out some of the limitations and possibilities in the use of comparative education, as well as elements for further reflection and research.
\end{abstract}

Keywords: Comparative Education. History of Comparative Education. Comparative Methodology. Interdisciplinarity. Comparatist Methodology. Interdisciplinarity.

* Professor Associado. Universidade Estadual do Oeste do Paraná - Campus de Foz do Iguaçu. Programa de Mestrado Interdisciplinar em Sociedade, Cultura e Fronteiras. Colegiado de Pedagogia. Email: <joaojorgecorrea@gmail.com> 


\section{Introdução}

A educação comparada historicamente dedicou-se à descrição de sistemas educacionais em desenvolvimento em vários países do mundo. Essa tarefa era desenvolvida por pesquisadores ligados ao campo educacional ou à área dos estudos da administração escolar. Eles viajavam pelo mundo coletando informações e aplicando-as em seus sistemas de ensino de origem. Eis o ponto de partida e também o de maior intensidade do debate, uma vez que a educação comparada não se reduz a esse fim tão somente.

Neste artigo pretende-se percorrer essa trajetória de construção do campo educacional comparatista, evidenciando sua história e os avanços que afetam o debate em função das melhorias sociais, econômicas e educacionais ocorridas nas últimas décadas.

Todavia, Ferreira (2009) nos alerta que comparar não é uma prerrogativa da educação, da pedagogia, ou de uma área específica do seu campo de investigação. Não é um procedimento metodológico inventado para se comparar somente sistemas educacionais. Durante seu desenvolvimento, a comparação esteve presente como recurso de pesquisa em várias áreas do conhecimento, como a história, a sociologia, o direito, a medicina, a literatura, entre outras.

Se é certo que desde seu início a educação comparada esteve vocacionada para compreender a dinâmica dos sistemas educacionais ou de aspectos com eles relacionados por via da comparação, essa ambição não se modificou até o presente. Todavia, a educação comparada não pode deixar de ser produto de uma história e de uma sociedade. A comparação sempre deve ter marcado a evolução do pensamento humano e, por isso, sempre esteve presente na própria construção do saber. No entanto, só num período recente da história utilizaram-na de forma sistemática. (FERREIRA, 2009, p. 137).

Neste texto discute-se a importância da educação comparada e do método comparatista na pesquisa educacional, bem como a sua relevância na área da política educacional. Ele está organizado a partir de dois parâmetros de análise. Na primeira parte faz-se uma breve incursão acerca dos principais enfoques em torno da educação comparada. $\mathrm{Na}$ segunda, apresenta-se uma exposição da sua arquitetura teórica, um esboço da história da constituição da educação comparada, a fim de contextualizar o conjunto da análise presente no texto, apresentando as características metodológicas dos principais autores que motivaram o debate inicial acerca do método comparatista. A ideia é mostrar o que foi e o que se tornou a educação comparada segundo os autores organizadores e, ao mesmo tempo, fundadores do método comparatista. Concluindo, são tecidas considerações sobre a presença do método comparatista em estudos e investigações contemporâneos, destacando seus limites e possibilidades de avanço no âmbito da educação.

\section{Questões preliminares acerca da educação comparada}

Existem várias classificações no campo da educação comparada. Adotou-se como referência histórica para construção dessa arquitetura alguns autores fundadores e organizadores do método comparatista para o estudo dos sistemas educacionais modernos, e autores comentadores que também elaboraram quadros históricos e conceituais.

Dentre os clássicos, foram abordados os seguintes: Marc-Antoine Jullien (1817), Kandel (1961), Lourenço Filho (1961), Kneller (1963), Kazamias \& Massialas (1965), King (1965), Noah \& Eckstein (1970), Vexliard (1970), Hans (1971), Bereday (1972), Márquez (1972). Em uma perspectiva mais contemporânea e crítica, pode-se citar: Bonitatibus (1989), Schriewer \& Pedró (1993), Nogueira (1994), Marcondes (2005), Ferreira (2008; 2009), Nóvoa (2009), Schriewer (2009).

De início ressalta-se que uma das principais questões refere-se às áreas e aos conteúdos específicos a partir dos quais a educação comparada delimitaria seus limites. O campo do debate se divide ao tratar da necessidade de uma especificidade teórica que ancore metodologicamente as investigações comparatistas.

A discussão contempla inclusive a dúvida se a educação comparada e o método comparatista por si só constituiriam um campo do saber e se poderiam receber o status de conhecimento científico (NÓVOA, 2009; FERREIRA; 2009).

Historicamente, a educação comparada expande seu desenvolvimento especificamente no 
mapeamento de sistemas educacionais, a fim de compreender as suas dinâmicas e complexidades. Ela se desenvolve basicamente a partir da necessidade de organização das redes de ensino, produto da expansão escolar, por parte dos Estados.

Nesse sentido preliminar, a comparação se dá por intermédio da experiência do outro na construção do seu próprio sistema escolar, que em última instância é uma ação do Estado. Para Nóvoa (2009, p. 24), "o outro é a razão de ser da educação comparada: o outro que serve de modelo ou de referência, que legitima as ações ou que impõe silêncios, que se imita ou que se coloniza".

A educação comparada faz parte de um campo de poderes dentro do qual se organizam centros e periferias, constroem-se práticas discursivas que consagram sentidos e definem limites. As práticas comparativas ajudam a difundir, em nível mundial, um modelo de escola que se desenvolveu na Europa, mas que se tornaria universal: a força deste modelo mede-se pela sua capacidade de ser olhado, não como o melhor sistema, mas como o único possível ou mesmo passível de ser imaginado. (NÓVOA, 2009, p. 24).

É na razão do entendimento comparativo em relação ao "outro", com o fim se refazer como outro diferente, que podemos encontrar as primeiras ações comparativas. Para Ferreira (2009, p. 143), “encontram-se indícios de educação comparada já na antiguidade, pois Tucídides, Heródoto e Xenofonte fizeram comparações que nos permitem distinguir o modo educativo ateniense do espartano e da educação grega da egípcia e da persa".

No entanto, a fase dos estudos sistemáticos não podia ter surgido antes de nossa época. De fato, somente ao longo dela os sistemas educativos nacionais, objeto preferencial dos estudos de educação comparada, começaram a afirmar-se, fruto de progressivas transformações econômicas, sociais, políticas e culturais das nações ocidentais. Por outro lado, era natural que a educação comparada nascesse no século XIX, ou seja, no mesmo ambiente cultural e científico em que desabrocharam a anatomia comparada, a literatura comparada, o direito comparado, entre outras ciências comparadas. (FERREIRA, 2009, p. 143).

A educação comparada é marcada pela complexidade e pela possibilidade de ser amplamente utilizada para levantamentos e estudos comparados que buscam a transformação educacional por meio da imposição de modelos de sucesso de gerenciamento educacional, obtidos a partir da importação de modelos estrangeiros. Essa é uma questão que merece destaque. Buscando esclarecer esse paradoxo, Ferreira (2008, p.126) afirma que é natural a educação comparada por vezes estar condicionada por interesses pragmáticos e imediatistas que promovem as políticas educacionais; e também é natural que suscite reações daqueles que não a entendem simplesmente como uma concepção técnica, e exigem dela uma postura mais crítica.

Esse paradoxo histórico sugere outra linha de reflexão, anteriormente apontada por Nogueira (1994), indicando que a educação comparada tem sido o centro de um debate que há muito ronda a sua história: como se constitui a sua identidade? Onde está firmada a sua base teórica? O que fundamenta o seu método?

São questões complexas, difíceis de serem respondidas, principalmente considerando a trajetória histórica na qual se constituem suas definições e conceitos, bem como os métodos de ação no campo da investigação científica.

É importante compreender a amplitude dos objetivos da educação comparada, assim como os caminhos que essa modalidade educacional percorre pelos diversos campos do saber e a relevância dos conhecimentos que produz e reproduz como balisadores de um tipo específico de metodologia de estudo e pesquisa.

Essa preocupação não é recente, tanto que nos anos cinquenta Hans (1951) já afirmava a necessidade de o tema ser analisado e debatido entre os meios acadêmicos. Imperava, então, a discordância entre os estudiosos do assunto sobre o campo de atuação da educação comparada e, também, sobre os próprios métodos que eram adotados nas investigações realizadas nessa área.

Presentemente pode-se dizer que existe importante produção acadêmica referente a esse tema, tanto no sentido de abordar as questões mais teóricas e metodológicas do campo da educação comparada, quanto na exposição de estudos comparados propriamente ditos entre realidades nacionais e internacionais. 
Nesse sentido, a crítica de Nogueira (1994), de que a produção científica sobre o tema é irrelevante, perde sentido. Haja vista, inclusive, o grau de agregação de diversas entidades e associações reunidas no Conselho Mundial de Sociedades de Educação Comparada, criado em 1970 com a finalidade de produzir estudos e construir conhecimento a partir da metodologia comparatista, bem como disseminar o conhecimento gerado através de publicações científicas e eventos de caráter acadêmico ${ }^{1}$.

Os estudos e levantamentos estatísticos e de perfil desses organismos buscam uniformizar medidas de enfrentamento dos problemas da educação mundial, através de programas específicos de ação que acabam se transformando em políticas educacionais nacionais nos países tomadores de recursos nos organismos internacionais.

No entendimento de Marcondes (2005),

a vinculação da educação comparada a esses organismos [...] revela-se negativa, pois limita o sentido dos estudos comparados em educação, servindo geralmente para legitimar reformas educativas nacionais e subsidiar financiamentos internacionais. (MARCONDES, 2005, p.144).

Percebe-se o risco de a educação comparada gerar ações nacionais que evidenciam uma característica de dependência cultural e de transferência educacional de outras experiências internacionais. Há um movimento por uma tênue linha que expõe o local às demandas globais. No entanto, em contextos globalizantes como o que vivemos atualmente, tornam-se inevitáveis os movimentos de internacionalização de experiências educacionais bem sucedidas. Nesses contextos, a educação comparada encontra-se em um "processo de reconstrução da educação num vaivém entre as referências nacionais e os enquadramentos internacionais" (NÓVOA, 2009, p.30).

O que se tem simultaneamente à expansão dos procedimentos de comparação é o que passou a se chamar de "internacionalização das análises e dos debates acerca de políticas no campo da educação";

\footnotetext{
Para um conhecimento do Conselho Mundial de Sociedades de Educação Comparada recomenda-se acesso ao seu endereço eletrônico, onde se pode observar a presença de associações nacionais abrangendo quase a totalidade dos continentes: $<$ http://www.wcces.net/index.html $>$. No Brasil, por exemplo, encontramos a Sociedade Brasileira de Educação Comparada (SBEC), criada em 1983: <http://www.sbec.org.br/index.php>.
}

de políticas que fossem, ao mesmo tempo, solução para os problemas locais, porém sem perder de vista as questões mais amplas inerentes à educação.

Entretanto, esses estudos também podem nos proporcionar um conhecimento mais amplo e complexo dos sistemas educacionais de vários países, de diversos contextos econômicos, culturais, políticos e sociais. Precisamos ter clareza dos métodos e instrumentos da educação comparada para perceber quais investigações comparadas "atestam a existência de modelos mundiais e de standards internacionais que parecem traduzir uma tendência de desenvolvimento global" (MARCONDES, 2005, p. 152).

Do ponto de vista de Kneller (1963), a educação comparada não pode prescindir de obter de outras áreas do conhecimento conteúdos capazes de esclarecer os seus próprios objetos de investigação. Isso significa dizer que a educação comparada atingirá pleno desenvolvimento se estiver diretamente relacionada e envolvida com uma ampla teoria educacional. Para Kazamias e Massialas (1965), essa questão é passível de ser analisada sob outro prisma, uma vez que a educação comparada pode ser realizada sistematicamente, tendo como suportes teóricos outros campos do saber, em função dos próprios objetos que se propõe compreender.

O problema é que suportes teóricos diversos podem gerar conflitos e até mesmo inconsistência de análise. Nesse sentido, Bereday (1972) considera que tal questão não se resolve tão facilmente assim. Pode-se afirmar que a educação comparada vem se caracterizando pela interculturalidade e interdisciplinaridade, e essa trajetória precisa ser acompanhada sistematicamente pelos autores comparatistas, sob o risco de perder o foco da investigação, do método e do status de uma área que contribui para o desenvolvimento das pesquisas educacionais que se dedicam à comparação.

Em seu desenvolvimento a educação comparada vem buscando encontrar o seu sentido, o seu objeto de estudo e os seus processos específicos de investigação. A sua aplicação prática é incontestável, à medida que, ao analisar comparativamente, por exemplo, sistemas educacionais, práticas pedagógicas, métodos de ensino, formas de financiamento, formação de professores, organizações escolares - em suma, a variada gama de possibilidades de pesquisa nos espaços escolares administrativos e 
pedagógicos - contribui para o entendimento desses elementos a partir da referência ao outro. Assim, o pesquisador comparatista não efetua "colagens" de uma experiência sobreposta a outra, mas analisa os pontos comuns e diversos, incluindo os problemas e respectivas soluções para os mesmos, evitando a reprodução de soluções já experimentadas no passado.

Para Ferreira (2008, p.125) "a educação comparada surgia, assim, num contexto histórico em que a expansão escolar e a afirmação da ciência se constituíam como pilares fundamentais do progresso, exactamente para poder contribuir para reformas educativas mais fundamentadas".

Na compreensão de Bonitatibus (1989), “a questão da definição de um objeto de estudo para a educação comparada" passa por um "espectro de afirmações", como, por exemplo: a educação comparada estuda os sistemas educativos, os sistemas nacionais de educação, os sistemas nacionais de ensino, os fatos pedagógicos, os fatos educacionais, o processo educativo ou as inter-relações entre educação e sociedade.

Dentre as fronteiras que estabelecem os limites da educação comparada é importante o esforço de Nóvoa (2009) ao elaborar uma linha de interpretação que busca compreender a construção histórica e os elementos positivos e negativos da prática comparatista. A análise de Nóvoa avança no sentido de mostrar elementos que trazem à tona um novo interesse pela educação comparada: problemas educacionais comuns aos países relacionados às demandas econômicas e culturais, a emergência de novos espaços culturais e de diversidade oriundos também da crise de um tipo de Estado, e a quebra das fronteiras no campo da produção do conhecimento nos conectando com diversas experiências educativas para além do território local (NÓVOA, 2009, p.26).

\section{A educação comparada no tempo: esboço de uma arquitetura}

Sistematicamente, a educação comparada teve início nos primórdios do século XIX, e recebeu várias classificações, segundo os diversos autores que buscaram sistematizá-la ao longo dos anos. Não se trata de algo definitivo e hermético, mas é o esboço de um movimento no tempo e o esforço na compreensão das principais características dos estudos comparados.
Remontando a educação comparada no tempo, em seus primeiros levantamentos mais sistemáticos, a fim de mapeá-la teoricamente, encontramos em Marc-Antoine Jullien o ponto de partida dessa forma de educação, no sentido de buscar sua sistematização em 1817, com a obra "Esquise et vues préliminaires d'un ouvrage sur l'éducation comparée". Em linhas gerais, a educação comparada se fundamentaria no estudo e compreensão da educação em todos os países, com o objetivo de se apropriar das características dos respectivos sistemas educacionais e compreender as suas especificidades nacionais e locais.

Observemos a seguir uma passagem de Jullien, citado por Ferreira (2009), esclarecendo o seu entendimento acerca da educação comparada.

Tratar-se-ia de organizar, sob os auspícios e com a proteção de um ou de vários príncipes soberanos, e com o concurso das sociedades de educação já existentes, uma comissão especial de educação, pouco numerosa, composta de homens encarregados de recolher, por eles mesmos e por intermédio de associados correspondentes, escolhidos com cuidado, os materiais de um trabalho geral sobre os estabelecimentos e os métodos de educação e de instrução dos diversos Estados da Europa, relacionados e comparados entre si sob este aspecto. Séries de questões sobre cada ramo da educação e da instrução, redigidas de antemão, classificadas sob títulos uniformes, seriam fornecidas a homens inteligentes e ativos, de julgamento seguro, de moralidade reconhecida, os quais procurariam a solução nos estabelecimentos de educação, particulares e públicos, que teriam a missão de visitar e de observar sobre diferentes pontos. [...]. (JULLIEN apud FERREIRA, 2009, p. 145-146).

Todavia, Hans (1971, p. 4) lembra que "historicamente, os estudos de educação comparada não foram comparativos no início, porque se limitavam a oferecer descrições e informações a respeito da educação dos países estrangeiros”. É a partir dessa constatação que a maioria das definições para educação comparada se sustenta. E é nesse aspecto que se encontram as suas limitações conceituais, as quais nos indicam que, presentemente, a educação comparada carece de uma ampliação da sua base conceitual, e é exatamente o que vem ocorrendo nos atuais estudos acerca do tema. 
Para Ferreira, "a educação comparada surgia, assim, num contexto histórico em que a expansão escolar e a afirmação da ciência se constituíam como pilares fundamentais do progresso, exactamente para poder contribuir para reformas educativas mais fundamentadas" (FERREIRA, 2008, p.125).

A educação comparada tem o foco central de suas investigações baseado no estudo dos sistemas educacionais nacionais e internacionais. Essa é uma ideia basicamente comum entre os comparatistas, apesar de que, durante o desenvolvimento teórico da própria educação, outros temas surgirão no âmbito da comparação.

Márquez (1972) define que

la educación comparada procura analizar y comparar las fuerzas que generan las diferencias entre los diversos sistemas nacionales de educación, ayuda a esclarecer las semejanzas y diferencias entre los diversos sistemas, al mismo tiempo que genera cierta sensibilidad para los problemas comunes y para las diferentes formas em que son resueltos bajo distintas condiciones nacionales. (MÁRQUEZ, 1972, p.19).

Para Kandel, a educação comparada se dedica às causas que atuam no desenvolvimento dos sistemas educacionais, bem como se ocupa da compreensão, inclusive, das semelhanças e diferenças entre distintos sistemas. Assim, "ao mesmo tempo, produz certa sensibilidade para os problemas comuns e para as diferentes formas em que são resolvidos sob diferentes condições nacionais" (KANDEL, 1961, p. 19).

Em Lourenço Filho (1961, p. 9) encontramos a ideia de que a educação é "um vasto domínio de estudos interdisciplinares" que não pode prescindir de dados históricos e sociais relativos a cada país e seus respectivos sistemas de ensino. Em sua análise, a educação comparada refere-se a um "certo tipo de estudos, primeiramente caracterizado pela escala de observação que emprega e, assim, a extensão do objeto que tem em vista elucidar: esses objetos são os sistemas nacionais de ensino" (LOURENÇO FILHO, 1961, p. 5).

No entendimento de Hans (1971, p. 18), “os sistemas nacionais de educação são a expressão exterior do caráter nacional e, como tal, distinguem uma nação da outra".

Seguindo outra linha de reflexão, distinta da ideia dos sistemas de ensino, King (1965) afirma que a educação comparada é o estudo (comparado) do processo educativo; logo, não pode simplificar-se aos sistemas de ensino, ou simplesmente reduzir-se nas comparações entre diversos países, ou nas comparações de realidades dispersas e diversas.

Para Bonitatibus (1989) a educação comparada pode ser apresentada a partir de cinco periodizações baseadas nas construções teóricas dos principais formuladores e compiladores comparatistas: Schneider (1966), Noah; Eckstein (1970), Vexliard (1970), Bereday (1972) e Márquez (1972).

Schneider, em obra de 1966, "La pedagogia comparada: su história, sus princípios y sus métodos", apresenta a educação comparada em duas fases: assistemática ou pré-científica, e sistemática ou científica. Essas duas fases representariam a passagem do tratamento do objeto sob investigação de maneira ocasional ou assistemática, como se prefere chamar, na qual ele não é analisado com o rigor científico adequado, ficando apenas em sua superficialidade aparente, para uma fase mais complexa de investigação e apropriação do objeto. No caso dos sistemas de ensino a abordagem inicial seria muito preliminar, incipiente, mais baseada na aparência externa da organização de um determinado sistema de ensino, para depois receber um olhar mais acurado, por meio do qual se buscariam suas especificidades e aquelas compartilhadas com outros sistemas.

Em "La Ciencia de la Educación Comparada", Noah e Eckstein (1970) apontam cinco períodos ao sistematizar a origem, evolução e amadurecimento da metodologia comparada como instrumento de compreensão dos sistemas educacionais. A classificação é a seguinte: período dos viajantes, empréstimos educacionais (inquiridores), colaboração internacional, forças e fatores, explicação pelas ciências sociais.

O período dos viajantes se caracteriza como "las primeras y más ingênuas observaciones de educación comparada [...] estos informes era esencialmente obra de aficcionados [...] la curiosidad era el primer motivo de esos viajes y el color local um factor de atracción em sus esbozos" (NOAH; ECKSTEIN, 1970, p. 19).

$\mathrm{Na}$ fase dos empréstimos educacionais (inquiridores) pessoas ligadas à educação e/ou governos percorriam países com o objetivo de recolher informações que pudessem servir de base e fundamento 
para a criação ou reorganização dos próprios sistemas de ensino dos sujeitos inquiridores. A diferença em relação à fase anterior é que nesta etapa os estudos e os levantamentos possuem melhor direcionamento para o que se deseja conhecer: as teorias e as metodologias pedagógicas, o financiamento, a organização dos sistemas educacionais e a formação docente (NOAH; ECKSTEIN, 1970).

A etapa da colaboração internacional é a busca do intercâmbio entre os países a partir da educação. Assim, "la trama resultante de contactos internacionales ayudaria por si sola a promover la comprensión así como el mejoramiento de las instituciones sociales, y em especial educativas, de todo el mundo" (NOAH; ECKSTEIN, 1970, p.20).

É na fase das forças e fatores que os estudos comparados começam a dar especial atenção teórica às complexas relações entre educação, sociedade e cultura, a fim de embasar as análises comparativas com maior respaldo explicativo. A preocupação histórica também caracteriza esse período, com a finalidade de explicar as transformações dos sistemas de ensino a partir de mudanças que começam a desenhar no passado remoto e recente.

Por fim, a explicação pelas ciências sociais, última fase entre aquelas sistematizadas por Noah \& Eckstein (1970), é o momento em que os comparatistas fazem uso dos métodos quantitativos adotados nas ciências sociais, objetivando a produção de dados e análises estatísticas sobre os sistemas de ensino.

Em "Pedagogia Comparada: métodos e problemas", Vexliard (1970) classifica a educação comparada em quatro períodos: a etapa estrutural, a fase dos inquiridores, as sistematizações teóricas e o período prospectivo.

A etapa estrutural é marcada pela obra "Esquisse", de Marc Antoine Jullien (1817), marco inicial da educação comparada, no qual se encontram os princípios metodológicos dos estudos comparados em educação.

$\mathrm{Na}$ fase dos inquiridores, pessoas ligadas à educação, enviadas pelos governos nacionais, percorriam países europeus e estados norte-americanos para estudar os seus sistemas de ensino. Através dos relatórios dessas viagens, elaboravam-se reformas nos países dos viajantes inquiridores e reformulações nos seus sistemas de ensino.
As sistematizações teóricas constituem um momento dos estudos comparados que é marcado por uma preocupação histórica, que busca dar conta de entender o surgimento dos sistemas de ensino e sua relação com o meio social em que se constroem e consolidam. Já o período prospectivo se preocupa com o futuro da educação e dos sistemas educacionais a partir do acúmulo de estudos realizados (VEXLIARD, 1970).

Em "Educación Comparada: teoría y metodologia", Márquez (1972) elabora a seguinte classificação: período pré-científico, científico, analítico-explicativo e comparativo.

No período pré-científico o exercício comparativo dos sistemas educacionais é ainda baseado nas experiências relatadas pelos viajantes, enquanto no período científico identifica-se a presença importante de Marc Antoine Jullien e outros comparatistas disseminados pela Europa e América do Sul (MÁRQUEZ, 1972).

$\mathrm{Na}$ fase analítico-explicativa o enfoque das investigações comparadas está marcado pelo elemento histórico, e em alguns momentos as abordagens seguem o viés filosófico e antropológico. Destacam-se, nessa fase, a busca pelo entendimento das construções dos sistemas de ensino no transcorrer dos tempos e, é importante frisar, as influências das formas de pensar e agir politicamente de determinadas conjunturas culturais, econômicas e sociais (MÁRQUEZ, 1972).

O período comparativo caracteriza-se pelas comparações dos elementos integrantes de uma dada forma de administração escolar e a maneira como se organizam os sistemas de ensino. Nessa etapa a educação comparada recebe fortes influências de elementos teóricos das ciências sociais, bem como de métodos de investigação específicos dessa área (MÁRQUEZ, 1972).

Para Bereday (1972), no "Método Comparado em Educação", a educação comparada pode ser classificada em três períodos: empréstimos, predição e análise.

O período dos empréstimos é marcado pela "catalogação de dados educacionais descritivos" que são comparados entre si, transplantando-se, posteriormente, as práticas e experiências que mais se destacavam. 
A segunda etapa dos estudos comparativos é composta por um processo de preparação que Bereday convencionou chamar de predição, "porque o fim do estudo comparativo já não era, primariamente, tomar emprestado o sistema de educação, mas predizer-lhe o sucesso provável num país à base da observação dos precedentes e de experiências semelhantes de outros países" (BEREDAY, 1972, p. 25).

A terceira fase refere-se ao período de análise, em que a preocupação central é "criar a unidade do mundo", ou uma espécie de "educação internacional", ou seja, "desenvolver teoria e métodos, na clara formulação das etapas de processos e mecanismos comparativos para facilitar esse alargamento de visão". Em suma, o que se busca, nesse período, é "o aumento das relações fraternais entre as nações, por meio da educação"; para conseguir isso, os sistemas educacionais deveriam estar emparelhados de uma forma que unificasse todos os demais sistemas mundiais (BEREDAY, 1972, p. 36).

É nessa lógica que, segundo Bereday (1972), a educação comparada e o método comparatista são fundamentais para os planejadores de políticas e ações educacionais.

Em seu Manual de Educación Comparada, Schriewer \& Pedró (1993, p. 22) confirmam a posição de Bereday acima referenciada:

Tanto entre los miembros de la comunidad científica como entre los políticos y administradores de la educación existe el convencimiento de que los estúdios comparativos pueden ser uma ayuda inestimable para el conocimiento em profundidad del fenômeno educativo y, más a fondo, para el progreso y el desarrollo educativo.

Podemos observar que as classificações se assemelham e as próprias razões e explicações apresentadas pelos autores analisados sugerem uma similitude no seu entendimento e forma de observar o surgimento e a evolução da educação comparada. Contudo, é comum entre esses autores a preocupação com a educação e a compreensão da forma como os sistemas de ensino se organizam no mundo.

Em síntese, observa-se uma linha contínua, evidentemente acompanhada de um aprofundamento reflexivo ao longo do tempo, entre aqueles a quem comumente denominou-se "fundadores do pensamento comparatista".
Passa-se de uma etapa assistemática para outra mais consistente, em que se percebe uma preocupação mais crítica com a investigação e o objeto sob estudo propriamente dito. Todavia, esse movimento segue um padrão em seu desenvolvimento:

Observa-se que de uma fase assistemática e/ ou pré-científica mais baseada nos empréstimos das experiências educacionais alheias por parte dos viajantes - que, na maioria das vezes, são pessoas ligadas a setores educacionais - vai-se passando por momentos mais consistentes nas experiências comparadas, até atingir etapas mais críticas, explicativas das realidades locais e nacionais, buscando uma comparação mais elaborada e analítica. Mas, devemos sempre lembrar que ao estudar em profundidade e comparativamente os sistemas educacionais nacionais, em última instância a ideia que perpassa esses levantamentos e estudos é fazer uma crítica às políticas educacionais, ou inspirar essas próprias políticas.

Contemporaneamente, em pesquisa realizada na década de noventa, Nóvoa (2009) traz ao público pesquisador e estudioso da educação comparada e do método comparatista outra forma de olhar para a sua arquitetura. Assim, inspirado em Michel Foucault, o referido autor elaborou um "mapa das comunidades discursivas da educação comparada".

Tendo em conta estas preocupações, que são antes pré-avisos, representei no espaço uma trintena de comparatistas, que produziram o essencial de seus trabalhos na segunda metade do século XX. A posição de cada autor foi determinada pela análise de alguns de seus trabalhos de referência, a partir de dois grandes critérios: adoção de teorias do consenso influenciadas por perspectivas funcionalistas baseadas na ideia de equilíbrio social, ou de teorias do conflito influenciadas por perspectivas críticas fundadas na ideia de mudança social, e adoção de abordagens descritivas baseadas em fenômenos e fatos observáveis considerados como realidades construídas por discursos que os situam em determinado espaço-tempo. (NÓVOA, 2009, p. 38, destaques meus).

Desse modo, a partir de um extenso levantamento dos autores comparatistas e/ou estudiosos do método comparado, Nóvoa (2009) elaborou duas dimensões, uma horizontal e outra vertical. $\mathrm{Na}$ primeira encontram-se as teorias e na segunda, 
as abordagens. A partir desse modelo o autor estabeleceu sete configurações que congregam as mais diversas perspectivas no campo da educação comparada: historicistas, positivistas, modernização, resolução de problemas, críticas, sistema mundial e sócio-históricas. Em cada uma das perspectivas elencadas o autor aponta os aspectos mais importantes identificados no levantamento realizado.

A perspectiva historicista foi o primeiro movimento no campo da educação comparada. Trata-se de comparações diretas entre a estrutura e as formas de funcionamento dos sistemas escolares internacionais e as experiências de âmbito nacional. Em linhas gerais, historicamente a educação comparada preocupou-se com a coleta de dados e informações da educação e do ensino desenvolvidos no mundo, bem como procurou evidenciar as suas eventuais modificações estruturais e organizacionais, visando a um constante desenvolvimento dos sistemas de ensino (NÓVOA, 2009).

A busca por um método comparativo e a prática de isolar elementos integrantes dos sistemas escolares para fins de estudo - por acreditar que esse procedimento seria o mais adequado e que a proposição e formulação de leis e ordenamentos contribuiriam por si só para a melhoria e transformação dos sistemas de ensino - constituem a perspectiva positivista no campo da comparação (NÓVOA, 2009).

Acreditar na educação como um elemento central no desenvolvimento e na modernização é a ideia que perpassa os argumentos e postulados da perspectiva pautada na modernização. Essa perspectiva entende a educação comparada como "um momento de tomada de decisão", uma vez que se propõe a construir "classificações e tipologias destinadas a orientar as políticas educativas" promovidas internamente nos países ou vindas de fora, sendo apresentadas por agências internacionais de produção de políticas públicas. Nessa perspectiva há, segundo Nóvoa (2009), uma forte ênfase por estudos marcadamente estatísticos, quantitativos e correlacionais.

O nível de conceitualização é relativamente fraco, dado que a teoria desempenha um papel instrumental. Em vez disso, tais autores estão sempre muito atentos à questão da transferência 'metodológica', quer dizer, à possibilidade de transferir de um contexto para o outro formas de abordar um mesmo problema. Apesar das preocupações tomadas, esta estratégia tende a 'tornar iguais' problemas diferentes, em virtude dos diferentes contextos. (NÓVOA, 2009, p. 42).

No campo da perspectiva da resolução de problemas tem-se uma ênfase marcadamente positivista: através do método comparatista seriam criadas leis gerais e/ou hipóteses, a fim de anunciar futuros problemas que deveriam ser solucionados através da dedução. Essa perspectiva recebe influência marcante das concepções de Dewey e Popper (NÓVOA, 2009 , p. 44). Sinteticamente, a abordagem comparativa seguiria um roteiro previamente definido, que basicamente partiria dos seguintes critérios: identificação de um problema educacional devidamente contextualizado; coleta de dados para comparação; elaboração de "tipos ideais"; e proposição de elementos de previsibilidade de resultados futuros para as ações e políticas propostas.

Por outro lado, a abordagem crítica, identificada e mapeada por Nóvoa (2009), representa uma cisão com as abordagens que a antecederam, em função do abandono da centralidade dos sistemas educacionais na condução das metodologias comparatistas. A nova forma de conduzir a reflexão comparatista tem respaldo na concepção crítica que se passa a elaborar a partir das ações dos organismos internacionais e dos efeitos negativos que elas começam a produzir na organização da educação e da política educativa nos países contratantes dos seus financiamentos.

A partir de uma referência aos estudos de Arnove, Altbach e Kelly (1982), Nóvoa aponta uma ruptura teórica com as demais perspectivas, que se fundamentaria em pelo menos três novos argumentos: a) as concepções comparatistas anteriores contribuíam fortemente "na manutenção de uma ordem social injusta e desigual", b) produziam políticas geradoras de "dependência em nível mundial" e c) enfatizavam análises educacionais pautadas nos "produtos da escola" (2009, p. 46).

Os estudos críticos no campo da educação comparada propõem uma inversão no alcance das análises comparatistas, ou seja, propõem que os sistemas deixem de ser o foco da atenção e que novos elementos sejam postos em evidência, como, por exemplo, os sujeitos envolvidos no processo de 
elaboração das políticas educativas. Destacam, entretanto, que essa discussão deve obrigatoriamente perpassar uma visão crítica da presença e atuação do Estado e das relações por ele engendradas no espaço de disputa pelas proposições educacionais.

A perspectiva do sistema mundial representa uma concepção complexa em função mesmo dos argumentos que apresenta e com os quais busca estabelecer rupturas, pois "vai contra algumas das lógicas tradicionais do trabalho de comparação", ou seja, contra "a ideia de que o mundo é constituído por uma quantidade de sociedades regionais ou nacionais com autonomia própria e histórias distintas" (NÓVOA, 2009, p. 47).

Essa forma de pensar a educação comparada acredita que no campo educacional existem elementos que se desprendem da ideia de uma nacionalidade ou regionalidade, colocando-se como realidades supranacionais e transfronteiriças, como é o caso da educação.

A ideia segundo a qual a educação não é uma instituição nacional, mas um componente racional de uma tecnologia mundial de progresso e de modernização é uma consequência pesada para o trabalho comparativo. Trata-se de uma ideia que é preciso relacionar com os processos de globalização, considerada como a intensificação das relações em nível mundial de forma a estabelecer laços entre localidades muito afastadas, de tal maneira que os acontecimento locais são influenciados por fenômenos que têm lugar muito longe (e vice-versa). (NÓVOA, 2009, p. 48).

Por fim, na concepção das perspectivas sócio-históricas há uma reformulação acerca da maneira como as comparações eram até então conduzidas. Propõe-se uma "passagem da análise dos fatos à análise do sentido histórico dos fatos" (NÓVOA, 2009, p. 49).

Do ponto de vista teórico, estes autores [do campo da perspectiva sociohistórica] tentam pôr em prática novas inteligibilidades, com base numa reconciliação entre a história e a comparação: é possível falar de um entendimento paradigmático, que pode conduzir os comparatistas a concederem mais atenção à história e à teoria, em detrimento da pura descrição e interpretação; aos conteúdos da educação e não apenas aos seus resultados; aos métodos qualitativos e etnográficos em vez do recurso exclusivo à quantificação e aos dados estatísticos. (PEREYRA apud NÓVOA, 2009, p. 49).

O levantamento teórico e conceitual acerca da educação comparada e dos métodos comparatistas evidenciados por Nóvoa em seu estudo possibilitou ao autor uma compreensão do movimento de reconfiguração nesse campo de investigação que se concretiza no seu próprio ciclo histórico, ou seja, a identificação de "novos problemas, novos modelos e novas abordagens", propriamente ditas (2009, p. 51).

Enfim, entre os estudiosos da educação comparada é comum a ideia de que o método comparatista contribui sobremaneira para o avanço no entendimento dos sistemas escolares mundiais. A questão que deve ser considerada é a maneira como o pesquisador trabalhará com estes dados, ou seja, os dados levantados pelos organismos nacionais e internacionais poderiam servir a vários interesses ao desenvolvermos o exercício da comparação.

Nesse sentido, o exercício da comparação pode ser fundamental para entendermos as nuances que as políticas centrais tomam em cada nação. A partir do uso do método comparativo é possível desvelarmos as razões do sucesso e fracasso de uma mesma política em realidades distintas, bem como as suas formas de gestão.

Discordâncias à parte, a educação comparada ao mesmo tempo em que sustenta seus estudos a partir da reflexão comparativa dos sistemas de ensino emergentes, quando da criação dos primeiros sistemas nacionais de educação, também é retroalimentada por estes. Isso quer dizer que à medida que os sistemas de ensino nacionais se desenvolvem, aprimorando e consolidando políticas e programas educacionais, também fortalecem a própria comparação.

Todavia, dentre as preocupações dos autores mais atuais no estudo e na compreensão da educação comparada, algumas merecem destaque: a questão da forma como se constitui a educação comparada e os seus referenciais teóricos e metodológicos.

Acerca da constituição da educação comparada, um elemento sempre presente em seus estudos e pesquisas é a figura do Estado nacional. De certa forma isso é compreensível, pois é por intermédio da atuação dos estados nacionais que se dá a criação, organização e expansão dos primeiros sistemas 
de ensino. E como o objetivo dos primeiros comparatistas era observar e tomar experiências como modelo desses sistemas, compreende-se a sua vinculação mais próxima com o Estado.

Entretanto, passada a fase exploratória e das compilações, bem como da evolução e aprimoramento dos sistemas de ensino pelo mundo, deve a educação comparada voltar-se para outras questões, inclusive para os próprios problemas gerados pela transposição de modelos de sistemas escolares a partir de realidades desconexas daquelas em que esses modelos foram aplicados e desenvolvidos. A atual configuração da educação no mundo contemporâneo estimula e promove o interesse pela comparação e compreensão de certos elementos comuns às formas que, em cada país, a organização das suas estruturas educacionais toma.

\section{Considerações finais}

Neste artigo buscou-se uma compreensão histórico-conceitual da educação comparada a partir dos principais autores que a constituíram como campo de atuação e investigação, bem como das formas metodológicas que os mesmos adotaram, diversificadamente, enquanto construção de um marco teórico para a descrição e análise dos sistemas educacionais.

Entretanto, como ressaltamos no início do texto, a comparação não está restrita ao círculo educacional e pedagógico, tendo servido teórica e metodologicamente a outros campos do saber. Pode-se dizer que a educação comparada, por adotar metodologia comum a outras áreas do conhecimento, atrai para seu o horizonte analítico a contribuição de outras ciências, tornando-se, durante o seu desenvolvimento, um referencial marcadamente interdisciplinar.

O texto procurou dar conta de uma incursão acerca dos principais enfoques em torno da educação comparada, bem como de uma exposição da sua arquitetura teórica, passando de perspectivas não-críticas para outras de caráter mais elaborado teoricamente.

Em síntese, pode-se reafirmar que existe uma diversidade de classificações na educação comparada, bem como autores cujo entendimento é fundamental para essa compreensão, como, por exemplo, e citando apenas alguns: Marc-Antoine Jullien, Bereday, Hans, Kandel, Kazamias \& Massialas, King, Kneller, Lourenço Filho, Márquez, Noah \& Eckstein e Vexliard. Contemporaneamente se fez alusão a Bonitatibus, Ferreira, Marcondes, Nogueira, Nóvoa, Schriewer, Schriewer \& Pedró.

Em torno da arquitetura da educação comparada - arquitetura essa construída a partir das experiências de pesquisa dos autores citados - foi possível observar uma espécie de arco teórico e metodológico que se torna mais visível com os estudos de Nóvoa (2009). Nesse arco encontramos desde as perspectivas mais positivistas, passando por análises comparatistas mais críticas, até o oposto evidenciado nas tendências mais preocupadas com novos elementos surgidos na contemporaneidade e que afetam as metodologias comparatistas.

Certamente, uma das ideias fortes no debate refere-se à metodologia dos estudos comparados e, nesse sentido, à compreensão do entendimento conceitual do "outro" em comparação. Historicamente, comparam-se realidades diversas. Como estamos tratando de sistemas educacionais, é importante destacar que a realidade organizacional do aparelho educativo de um dado país, por exemplo, em função do seu sucesso no local de origem, serviria como solução para os problemas educativos em outros países. Evidentemente, raciocínio similar pode ser elaborado a partir das experiências internas em um mesmo país.

Nessa transmissão se evidenciam as maiores dificuldades para os estudiosos e pesquisadores comparatistas: a transposição da experiência de "um outro" para dar conta da realidade diversa "daquele outro" que se faz produzir em realidades e contextos diversos e até mesmo distantes. É como se não houvesse subjetividade na identificação, elaboração e desenvolvimento de ações educacionais no contexto de nações e regiões diversas.

Com o intuito de dar mais visibilidade à questão, é importante reafirmar passagem citada no conjunto do texto: "O outro é a razão de ser da educação comparada: o outro que serve de modelo ou de referência, que legitima as ações ou que impõe silêncios, que se imita ou que se coloniza". (NÓVOA, 2009, p. 24).

Uma variável certamente relevante no debate das investigações comparatistas diz respeito à sua 
vinculação com os estudos e pesquisas desenvolvidos por organismos internacionais. Nesse sentido, Ferreira (2008) indica que é natural a educação comparada estar condicionada por interesses pragmáticos e imediatistas daqueles que promovem as políticas educacionais; e também é natural que essa forma de educação suscite reações daqueles que não a entendem simplesmente como uma concepção técnica, e exigem uma postura mais crítica.

Internacionalmente, tanto do ponto de vista técnico quanto do teórico, as referências da educação comparada são os estudos desenvolvidos pelo Banco Mundial, UNESCO e OCDE. Essas instituições fazem uso do método comparatista recolhendo dados dos diversos elementos que compõem os sistemas educacionais, como, por exemplo: avaliação, formas de financiamento, instrumentos de formação de professores, produção de livros didáticos, mecanismos de gestão escolar, entre outros. De posse dessas informações buscam "enquadrá-las" em realidades diversas daquelas que as produziram e informar ao "outro" o que é melhor para si em termos de política educacional em contextos globalizantes.

Presentemente, a educação comparada encontra-se em um momento bastante dinâmico, abordando temáticas diversas, passando por leituras antropológicas, orientações mais marxistas, e atingindo os olhares presentes nas tendências pós-modernas. Uma série de estudos vem sendo desenvolvida, tanto no âmbito nacional quanto no internacional. Nacionalmente, podemos fazer referência ao grupo de pesquisadores vinculados à SBEC, com sobeja produção científica articulando interações com estudiosos do entorno da América Latina. No âmbito nacional também se destacam os estudos comparados desenvolvidos pelo INEP, mas esses em uma perspectiva mais técnica do que teórica. Por vezes, a perspectiva técnica é mais sistematizadora dos resultados de políticas educacionais.

Concluindo, pode-se dizer que a educação comparada vem atravessando um momento importante no meio acadêmico, como resultado, em parte, do próprio movimento, que tem perpassado pela reflexão e auto-reflexão dos seus pesquisadores e, também, por uma renovação no interesse pela comparação (MADEIRA, 2009). A diversidade de posicionamentos no campo teórico e metodológico é outro elemento que vem aguçando o espírito crítico no escopo comparatista, bem como a divergência e convergência entre seus autores fundamentais.

Enfim, devem ser apontados alguns elementos que merecem aprofundamento no debate. Um deles é a questão do contexto, como categoria central e fundamental no exercício metodológico da comparação, devidamente associado ao conceito de globalização. Este, por sua vez, marcado pela complexidade, pela diversidade, pelas relações entre nacional e internacional e entre local e global. Certamente, trata-se de elementos em fronteiras de reflexão e aplicabilidade no campo educacional e, notadamente, na gestão das políticas públicas.

\section{Referências}

BEREDAY, G. Z. F. Método comparado em educação. São Paulo: Editora Nacional, 1972.

BONITATIBUS, S. G. Educação comparada: conceito, evolução, métodos. São Paulo: EPU, 1989.

FERREIRA, A. G. O sentido da educação comparada: uma compreensão sobre a construção de uma identidade. Educação, Porto Alegre, v.31, n.2, p.124-138, maio/ago. 2008.

FERREIRA, A. G. O sentido da educação comparada: uma compreensão sobre a construção de uma identidade. In: MARTINEZ, S. A.; SOUZA, D. B. (Orgs.). Educação comparada: rotas de além-mar. São Paulo: Xamã, 2009. p. 137-166.

HANS, N. Educação comparada. 2. ed. São Paulo: Nacional, 1971.

KANDEL, I. L. Uma nova era em educação: estudo comparativo. Rio de Janeiro: Fundo de Cultura, 1961.

KAZAMIAS, A. A.; MASSIALAS, B. G. Tradition and change in education. Prentice Hall, New York, 1965.

KING, E. O propósito da educação comparada. Comparative Education Review, v.1, n.3, jun. 1965.

KNELLER, G. F. The prospects of comparative education. International Review of Education, v. 9, n.4, 1963.

JULLIEN, M-A. Esboço e perspectivas preliminares de uma obra de educação comparada. Coimbra, s.e., 1967. (Obra original de 1817).

LOURENÇO FILHO, M. B. Educação comparada. São Paulo: Melhoramentos, 1961.

MADEIRA, A. I. O campo da educação comparada: do simbolismo fundacional à renovação das lógicas de investigação. In: MARTINEZ, S. A.; SOUZA, D. B. 
(Orgs.). Educação comparada: rotas de além-mar. São Paulo: Xamã, 2009. p. 105-136.

MARCONDES, M. A. S. Educação comparada: perspectivas teóricas e investigações. Eccos - Revista Científica, São Paulo, Uninove, v.7, n.1, p.139-163, jun. 2005.

MÁRQUEZ, A. D. Educación comparada: teoria y metodologia. Buenos Aires, Argentina: El Ateneo, 1972.

NOAH, H. J.; ECKSTEIN, M. A. La ciencia de la educación comparada. Buenos Aires, Argentina, 1970.

NOGUEIRA, S. M. A. Educação comparada e o pensamento educacional criador: o essencial de uma relação fertilizadora. Em Aberto, Brasília, ano 14, n.64, p.35-42, out./dez. 1994.

NÓVOA, A. Modelos de análise em educação comparada: o campo e o mapa. In: MARTINEZ, S. A.; SOUZA, D. B. (Orgs.). Educação comparada: rotas de além-mar. São Paulo: Xamã, 2009. p. 23-62.

SCHENEIDER, F. La Pedagogía comprada: su historia, sus princípios y SUS métodos. Editorial Herder, Barcelona, 1966.

SCHRIEWER, J.; PEDRÓ, F. (Eds.). Manual de educación comparada: teorias, investigaciones, perspectivas. Barcelona: Universitas, 1993.

SCHRIEWER, J. Aceitando os desafios da complexidade: metodologia de educação comparada em transição. In: MARTINEZ, S. A.; SOUZA, D. B. (Orgs.). Educação comparada: rotas de além-mar. São Paulo: Xamã, 2009. p. 63-104.

VEXLIARD, A. Pedagogia comparada: métodos e problemas. São Paulo: Nacional, 1970.

Data de submissão: 04/09/2012

Data de aceite: $18 / 10 / 2012$ 